\title{
GESTÃo ESTRATÉGICA: uma análise do primeiro ciclo de implementação em uma Instituição de Ensino Superior Confessional da Bahia [2014-2018]
}

\begin{abstract}
TÂNIA MOURA BENEVIDES
Universidade Federal da Bahia (UFBA), Faculdade Adventista da Bahia (FADBA). Doutora em Administração pela Universidade Federal da Bahia (2012), Mestre em Administração Estratégica pela Universidade Salvador (2003), Graduada em Administração pela Faculdade Ruy Barbosa (1996). ORCID: 0000-0001-9191-7831. E-mail: taniamoura2511@gmail.com
\end{abstract}

\section{MARCO ANTÔNIO LEAL GÓES}

União Boliviana da IASD (Bolívia), Mestre em Administração pela Universidade Federal da Bahia (2019), Graduado em Psicologia pela Universidade da Amazônia (1991). Diretor de Departamento de Educação União Boliviana da IASD. ORCID: 0000-0002-9798-9745.

E-mail: marco.goes@adventistas.org.bo

\section{JÉSSICA NASCIMENTO DE OLIVEIRA}

Graduada em Administração pela Universidade Federal da Bahia (UFBA). Pesquisadora no campo de Segurança Pública e membro do grupo de pesquisa Águas (UFBA), atuando no projeto Qualidade do Ambiente Urbano de Salvador - QUALISalvador. Extensionista em Política e Estratégia (2017) pela Associação dos Diplomados da Escola Superior de Guerra, Delegacia da Bahia, ADESGBA. ORCID: 0000-0001-8542-9364.

E-mail: jessiica.oliveira3@gmail.com 


\section{GESTÃO ESTRATÉGICA: uma análise do primeiro ciclo de implementação em uma Instituição de Ensino Superior Confessional da Bahia [2014-2018]}

O presente estudo teve como objetivo analisar a implementação do primeiro ciclo [2014-2018] de gestão estratégica em uma instituição de ensino superior confessional da Bahia, a Faculdade Adventista da Bahia (FADBA). Para a realização desse estudo partiu-se das pesquisas bibliográfica e documental para alicerçar o estudo. A seguir foi realizada a pesquisa de campo, utilizando-se da entrevista e do questionário para levantamento de dados primários. Ao final do processo pode-se constatar que a instituição possui fatores diferenciais que favorecem a implementação da gestão estratégica tais como: filosofia denominacional consolidada, alinhamento de procedimentos, hierarquia de funções definidas e respeitadas, e um planejamento estratégico elaborado de acordo com as necessidades da organização.

Palavras-chave: Gestão. Gestão Estratégica. Instituição Confessional.

\section{GESTIÓN ESTRATÉGICA: un análisis del primer ciclo de implementación en una Institución Confesional de Educación Superior en Bahia [2014-2018]}

El presente estudio tuvo como objetivo analizar la implementación del primer ciclo [2014-2018] de gestión estratégica en una institución confesional de educación superior de Bahía, el Colegio Adventista de Bahía (FADBA). Para llevar a cabo este estudio, se utilizó una investigación bibliográfica y documental para apoyar el estudio. Se llevó a cabo la siguiente investigación de campo, utilizando la entrevista y el cuestionario para recopilar datos primarios. Al final del proceso se puede ver que la institución tiene factores diferenciales que favorecen la implementación de la gestión estratégica tales como: filosofía confesional consolidada, alineación de procedimientos, jerarquía de funciones definidas y respetadas, y una planificación estratégica elaborada según las necesidades de la organización.

Palabras clave: Gestión. Gestión estratégica. Institución confesional.

\section{STRATEGIC MANAGEMENT: an analysis of the first implementation cycle in a confessional higher education institution in BAHIA [2014-2018]}

El presente estudio tuvo como objetivo analizar la implementación del primer ciclo [2014-2018] de gestión estratégica en una institución confesional de educación superior de Bahía, el Colegio Adventista de Bahía (FADBA). Para llevar a cabo este estudio, se utilizó una investigación bibliográfica y documental para apoyar el estudio. Se llevó a cabo la siguiente investigación de campo, utilizando la entrevista y el cuestionario para recopilar datos primarios. Al final del proceso se puede ver que la institución tiene factores diferenciales que favorecen la implementación de la gestión estratégica tales como: filosofía confesional consolidada, alineación de procedimientos, jerarquía de funciones definidas y respetadas, y una planificación estratégica elaborada según las necesidades de la organización.

Keywords: Management. Strategic management. Confessional Institution. 


\section{GESTÃO ESTRATÉGICA: UMA ANÁLISE DO PRIMEIRO CICLO DE IMPLEMENTAÇÃO EM UMA INSTITUIÇÃO DE ENSINO SUPERIOR CONFESSIONAL DA BAHIA [2014-2018]}

\section{Introdução}

A literatura sobre gestão estratégica, nas últimas décadas, se avolumou com o objetivo de analisar o campo de gestão das organizações, dada complexidade dessas. Entretanto, como destaca Almeida Filho (2014), nem sempre foi assim, pois esse campo de conhecimento passou por quatro momentos distintos. São eles: até o final da década de 1950 - quando não se utilizava o adjetivo estratégico ou o substantivo estratégia atrelado a denominação "gestão, relegando-os ao uso militar; ao longo da década de 1960 - quando a percepção do dinamismo dos mercados e a elevação da turbulência no contexto exigiram abordagens mais dinâmicas e sistêmicas, fazendo com que organizações distintas criassem departamentos de business strategy, o que vai se refletir nas escolas de administração. Assim, as empresas com gestão mais avançada e o setor público, introduziram-se práticas do planejamento estratégico. É nesse período que Igor Ansoff escreve o livro intitulado "From Strategic Planning to Strategic Management"; ao final dos anos 1980 todas essas mudanças vieram a influenciar as práticas de gestão das organizações. Nesse terceiro momento, emerge o paradigma porteriano de planejamento estratégico; por fim, ao final dos anos 1990 e no início do século XXI, "as provocações inicialmente acadêmicas que levaram à quarta geração das tecnologias de planejamento e administração estratégica se difundem grandemente" (p.279). Essa nova forma de gerir estrategicamente organizações se estrutura com o trabalho de Kaplan e Norton, uma metodologia denominada de Balanced Scorecard (BSC). Aqui destaca-se a difusão da abordagem crítica de Mintzberg e seus colaboradores.

As muitas definições dadas para a terminologia estratégia, remete a ideia de tratar a organização como um todo, buscando entender as multifaces de suas interações internas e externas capazes de criar ações coletivas que alcancem todos os seus níveis. Nesse sentido, a estratégia foi definida por Porter (1989) como uma forma de criar uma posição exclusiva e valiosa, envolvendo um diferente conjunto de atividades compatíveis entre si; por Mintzberg (2009) como um padrão, um fluxo de ações ou decisões; por Kaplan e Norton (1997) como uma forma de criar uma posição

\section{plurais}


exclusiva e valiosa, envolvendo um diferente conjunto de atividades entre si. Assim, entende-se que a gestão estratégica se popularizou, dada eficácia e relevância para atingimento de resultados organizacionais, tornando-se uma prática social.

Costa (2015) observa que os ciclos das mudanças, estando cada vez menores, exigem que o tempo de reação das empresas e entidades se encurte. Tendências, mudanças de valores, novas tecnologias, surgimento ou desaparecimento de agentes de mercado, ocorrem na atualidade com maior frequência e com menor horizonte de previsibilidade. Segundo Xavier e Sobrinho (2002) a prestação de um serviço cada vez melhor, também tem levado as organizações educacionais ao campo da competitividade. Assim, a educação, em toda sua complexidade, vem sofrendo transformações significativas nos últimos vinte anos em função de dois fenômenos: o intensivo uso da tecnologia e o processo mais concreto de globalização. Os processos formativos se modificaram de forma definitiva, influenciando as agendas pedagógicas, as estruturas organizativas e os modelos organizacionais da ciência do ensino-aprendizagem. A educação deve ser entendida em seu contexto geral, com um elevado propósito transformador. Para a educação, que trabalha quase que exclusivamente com a transformação do ser humano em um processo contínuo de mudança, imaginá-la estanque ou aprisionada a um único modelo de gestão, a faz contraditória ao fim último de sua razão de ser. Neste sentido, estudar a gestão estratégica em ambientes de instituições educacionais é desenvolver aprendizado sobre as ações e interações institucionais que em última instância, pode afetar o processo de transformação do indivíduo e sua relação com os serviços oferecidos.

Levando-se em consideração que as organizações educacionais também apresentam a necessidade de garantir o direcionamento e atingimento do propósito organizacional, esta pesquisa se destina a responder a seguinte pergunta de partida: Qual o resultado, na percepção dos gestores e colaboradores de uma instituição confessional de educação superior no estado da Bahia, da implementação do primeiro ciclo de gestão estratégica [2014 a 2018] impactou a instituição?

O objetivo geral desse estudo é o de identificar a percepção de gestores e colaboradores em relação ao resultado da implementação da gestão estratégica na Faculdade Adventista da Bahia (FADBA) no período de 2014 a 2018. Especificamente buscou-se: descrever o modelo de gestão estratégica adotado na IES estudada; caracterizar o perfil do público-alvo e a sua influência no processo de gestão estratégica; identificar os principais impactos gerados com a adoção da gestão 
estratégica na IES; e analisar a gestão e a efetividade da estratégia no âmbito da organização em pesquisa.

Esta pesquisa se mostra relevante por abordar uma questão central no processo de gestão, que é o delineamento das etapas/estratégias planejadas para a organização, com consequente aprimoramento dos colaboradores que leve à melhoria do serviço prestado e a satisfação do cliente; também busca compreender o desenvolvimento das organizações educacionais, tendo em vista o papel delas na formação do indivíduo e difusão do conhecimento, observando o uso e a adequação do uso da gestão estratégica nesse contexto. Neste aspecto, gestores educacionais, bem como todos os demais colaboradores, precisam se adequar, atualizar e procurar modificar sua postura, frente ao trabalho administrativo-pedagógico e as outras áreas do gerenciamento educativo, afim de acompanhar as constantes mudanças e avanços ocorridos na atualidade, transformando-se em elementos fundamentais na concretização de uma gestão educativa mais eficiente. Assim, as novas formas de organização do trabalho dependerão dos direcionamentos e objetivos estratégicos da empresa (FERNANDES, 2013).

Este artigo está organizado em cinco seções. A primeira seção é a introdução, onde estão os elementos delineadores da pesquisa. Na segunda seção está o referencial teórico, que apresenta a fundamentação teórica relacionada a gestão estratégica, os modelos adotados e seus principais conceitos. A terceira seção trata da metodologia adotada. Na quarta seção está a caracterização da instituição pesquisada e o delineamento de sua estrutura de gestão. As considerações finais constituem a última seção desse artigo.

\section{Gestão Estratégica}

Estratego é o termo grego para estratégia (VOLTOLINI, 2004) e estava diretamente relacionado ao cargo de um comandante da antiga Atenas. No livro "A Arte de Guerra", atribuído a Sun Tzu e datado de 500 a. C. já se encontrava o emprego da terminologia. Os séculos XIX e XX são marcados pelo surgimento de inúmeras literaturas que passam a incorporar estratégia aos mais variados ramos do saber humano, em especial às empresas e aos negócios (TOMMASI; WARD; HADDAD, 1996).

\section{plurais


A partir da década de 1960, o interesse pela aplicabilidade da estratégia nas empresas toma impulso nos estudos acadêmicos de vários autores tais como: Igor Ansoff (1960), Henry Mintzberg (1970), Michel Porter (1980), Kaplan e Norton (1980), e Richard Whittington (1990). As bases teóricas de Ansoff centravam-se, dentre outros pilares, na formulação estratégica como responsabilidade dos altos executivos; já em Mintzberg os estudos sobre estratégia recebem uma grande relevância e o foco agora passa a ser o crescimento por meio da expansão e diversificação. Em Michel Porter o conceito está no conjunto de atividades afins, capazes de conferir a empresa uma vantagem competitiva. Com Kaplan e Norton a visão sistêmica de gestão estratégica é fortalecida com controle e acompanhamento. Em Richard Whittington alianças, parcerias compõem a gestão estratégica, conferem a estratégia um status de prática social com ênfase na interação de todos os autores da estratégia (BULGACOV et al, 2007).

Analisando os autores e a linha do tempo de seus estudos, percebe-se que a gestão estratégica (e a formulação de seu conceito) vem em um processo de amadurecimento que envolve renovação e acomodação de um espectro diverso de realidades empresariais que impossibilita definir um único modelo de gestão que atenda todas as necessidades de uma organização. Agrega-se ainda a essa percepção, o fato de que o desenvolvimento dos estudos da estratégia é, em certa medida, resultante do processo de maturação da gestão organizacional, envolvendo mudanças e sustentabilidade das empresas, revelando diversidades e complexidades para sua definição (BULGACOV, 2007).

Mintzberg, Ahlstrand e Lampel (2000) propuseram uma conceituação ampliada para a compreensão da gestão estratégica que se popularizou como os 5 Ps - Plano, Pretexto, Padrão, Posição e Perspectiva. Para além Mintzberg (2009, p. 27) define estratégia como “[...] uma perspectiva compartilhada pelos membros de uma organização, por sua intensões ou por suas ações."

Acompanhando essa evolução, alguns estudos do uso de ferramentas de gestão estratégica na área educacional passam a surgir, reforçando a disseminação de conceitos e pesquisas neste campo de estudo. Faz-se necessário destacar que ainda há pouca literatura que trate desta especificidade de aplicação da gestão estratégica na aérea educacional, sendo estas premissas iniciais já suficientes para a inserção da gestão estratégica educacional como objeto desta pesquisa. Além disso, temos que considerar que o setor de educação adquiriu funções fundamentais para o desenvolvimento econômico das nações como apontam os estudos de Santos (2002); e Porter (1989). 
Caggy e Benevides (2018) reforçam que há um grande interesse na análise e compreensão dos reais motivos de êxito ou fracasso das empresas. Para uma compreensão mais positiva do que se pretende neste trabalho, os conceitos do cenário da administração de empresas são os que melhor explicitam os objetivos aqui propostos. A conceituação de estratégia como sendo um conjunto contínuo de objetivos e de políticas capazes de guiar e orientar o comportamento da empresa em curto, médio e longo prazo, em um processo agregado ao maior conhecimento possível do ideal de futuro, que possibilite tomar decisões atuais que envolvam riscos, que permita organizar sistematicamente as atividades necessárias à execução de decisões, através de uma retroalimentação capaz de mensurar os resultados, é o que melhor descreve o que se propõe nessa pesquisa.

Após o declínio do planejamento estratégico nos anos de 1980 e com a ascensão dos novos modelos de gestão - qualidade total, reengenharia, seis sigmas, entre outros - a preocupação com a estratégia foi relegada a segundo plano. Com a intensificação das incertezas, no final doas anos de 1990 essa temática volta ao centro do debate em gestão, já que os gestores demandavam uma nova forma de ordenamento organizacional, capaz de construir uma estratégia em torno de uma clara proposta de valor para o cliente; desenvolver estratégias de fora para dentro tendo como base as expectativas dos clientes, acionistas e investidores; melhorar o alinhamento da estratégia às mudanças de mercado; melhorar a comunicação da empresa com seus stakeholders; e garantir a sustentabilidade e crescimento organizacionais. Herrero Filho (2005, p. 03) diz que "a essência da gestão estratégica é elaborar, por meio de uma abordagem inovadora e criativa, uma estratégia [...] que assegure o êxito da organização [...], ao mesmo tempo que constrói as competências essenciais $[\ldots] "$.

A fim de fazer cumprir a estratégia estruturada para a organização/instituição faz-se necessário estruturar um modelo de gestão estratégica. A gestão dita estratégica se coaduna com uma técnica administrativa que, através da análise do ambiente interno e externo de uma organização, cria a consciência de suas oportunidades e ameaças, dos seus pontos fortes e fracos para o cumprimento de sua missão e, através desta consciência, estabelece o propósito de direção que a organização deverá seguir para aproveitar as oportunidades e evitar os riscos (ANSOFF, 1990; PORTER, 1989; MINTZBERG, 2000).

Uma forma de viabilizar tais análises é implantar o Balanced Scorecard (BSC), uma das metodologias de medição e avaliação do desempenho organizacional mais difundida no mundo $\mathrm{O}$

\section{plurais


BSC fornece uma estrutura para transformar a estratégia em ação e através do Mapa Estratégico permite visualizar hipóteses causa-efeito permitindo antecipar uma visão mais clara sobre o futuro do negócio. Busca fundamentalmente complementar os indicadores tradicionalmente utilizados para avaliar o desempenho das empresas, combinando indicadores financeiros e não financeiros, alcançando assim um equilíbrio entre o desempenho da organização no dia-a-dia e a construção de um futuro promissor, cumprindo assim a missão organizacional. O BSC sugere olhar para a organização de quatro perspectivas, cada uma deve responder a uma pergunta específica: desenvolvimento e aprendizado: podemos continuar a melhorar e criar valor?; negócio interno: em que devemos nos destacar?; do cliente: como os clientes nos veem?; e financeiro: como olhamos nos olhos dos acionistas? (KAPLAN E NORTON, 2017).

O BSC permite uma visão integrada e balanceada da empresa, descrevendo a estratégia de forma clara, através de objetivos estratégicos, que são agrupados em quatro perspectivas. São elas: Financeira, Cliente, Processos Internos, Aprendizado e Crescimento. No processo de traduzir a estratégia em objetivos e medidas mensuráveis, as quatro perspectivas (ou domínios) do Balanced Scorecard estabelecem um diálogo entre os formuladores da estratégia e os stakeholders da organização. As perspectivas do BSC são relacionadas entre si através de uma relação de causa e efeito, permitindo que os gestores/gerentes percebam as correlações entre diversas áreas e atividades, o que é compatível com o andamento de inúmeras iniciativas do mundo empresarial moderno, tais como: melhoria contínua, responsabilização das equipes e o processo de inovação (KAPLAN e NORTON, 2017).

Os estudos provenientes do Balanced Scorecard, realizados por Kaplan e Norton, entre 1992 e 2000, possibilitaram a identificação dos princípios de uma organização orientada pela estratégia e que, ao mesmo tempo, utiliza a nova ferramenta de gestão - 1) traduzir a Estratégia em Termos Operacionais; 2) Alinhar a Organização à Estratégia; 3) transformar a Estratégia em tarefa de todos; 4) converter a Estratégia em processo contínuo; 5) mobilizar a mudança por meio da liderança.

O BSC vai incorporando as principais ideias sobre gestão defendidas por Michael Porter, Gary Hamel, C.K. Prahalad, W. Edward De-ming, Michael Treacy, Fred Wiersema, Dave Ulrich, Peter Senge, Henry Mintzberg, Edgar Schein, Philip Crosby, Thomas Stewart, W. Chan Kim, Re-née Mauborgne, entre outros (HERRERO FILHO, 2005). As ideias são representadas pelos seguintes conceitos: organização orientada para a estratégia; mobilização de ativos intangíveis para a criação

\section{plupais}


de valor; insuficiências dos indicadores financeiros para gerenciar o negócio; equilíbrio entre objetivos de curto e longo prazos, entre medidas financeiras e não-financeiras e entre indicadores de tendências e de ocorrência; tradução de visão e missão em objetivos estratégicos mensuráveis e de fácil entendimento pelos colaboradores da organização; transformação da estratégia em responsabilidade da força de trabalho; e prontidão do capital intelectual. A abordagem do BSC como novo paradigma de gestão estratégica é de grande utilidade nos processos de aprendizagem, educação, simulação e implementação para as diferentes equipes.

\section{A Gestão Universitária}

No Brasil o ensino superior tem uma trajetória própria. Ribeiro (2011) apresenta a evolução do ensino superior brasileiro considerando a existência de três ciclos históricos. No primeiro ciclo [1550 - 1960], iniciado em 1550, com a fundação do primeiro colégio jesuíta no país, sediado na Bahia, então sede do Governo de Tomé de Souza, há uma evolução lenta que se caracteriza por pouca modificações, com o agravante de que seu crescimento se limita ao volume de recursos disponibilizados pelo Estado, sem a presença de investimentos privados. Somente em 1920 é criada a primeira universidade brasileira. Nesse período as vagas públicas não eram suficientes para atender à demanda por ensino superior. No segundo ciclo [1960 - 1990] é promulgada, em 20 de dezembro de 1961, a Lei n. ${ }^{\circ} 4.024$ - Lei de Diretrizes e Bases (LDB) - com o objetivo de regulamentar a expansão do ensino superior com a criação de órgãos - o CFE e os diversos Conselhos Estaduais de Educação (CEE) - que controlassem a implantação de novos cursos e instituições. Em 1968 ocorre a Reforma Universitária, que introduz um modelo acadêmico e administrativo para o ensino superior nacional pressupondo a intensificação do imbricamento entre as três dimensões do ensino superior - ensino, pesquisa e extensão.

De acordo com Almeida Filho (2014), nos anos 80 a nova Constituição institui a autonomia universitária. A autonomia didático-pedagógica conferida às universidades privadas garantiu o crescimento do segmento, fazendo-o atingir novos mercados - submetidos a menos controles governamentais promoveu a elevação do número de estabelecimentos privados. Finalmente, a utilização de recursos públicos dinamizou o setor privado, que passou a se dividir em entidades com e sem fins lucrativos. Na fase final desse ciclo o ensino superior se diversifica e se expande, surgindo propostas de alteração dos padrões de financiamento; de oferta de cursos voltados à educação profissional de menor duração; de incentivo ao maior uso de TIC, entre outras transformações.

\section{plupais}


O terceiro ciclo [1990 a atualidade] é marcado pela entrada, através de parcerias com IES privadas nacionais, de diversas IES internacionais em diferentes regiões do Brasil. Esse período recebe críticas à mercantilização e ao crescimento privado, tem foco na universalização, impõe legislação voltada a controles integrados e formas de financiamento; e viabiliza a oligopolização do segmento privado e retomada do crescimento do público. Nesse período se intensificam fusões e aquisições de IES privadas, a entrada de IES internacionais favorecendo-se a internacionalização e oligopolização do segmento (RIBEIRO, 2011). Essas diferentes fases formam um processo histórico evolutivo das instituições de ensino superior no Brasil, com impactos diretos em termos organizacionais e na capacidade de gestão destas instituições.

A instituição estudada se insere no contexto das instituições confessionais e, portanto, não tem a configuração de uma instituição pública, pois ainda não é uma universidade, trata-se de uma unidade da Igreja Adventista, que localizada na Bahia desenvolve as suas atividades atendendo ao que determina a regulação do MEC. AFADBA busca desenvolver as atividades de ensino, pesquisa e extensão. Para tal faz-se necessária a atividade de gestão.

Silva (2019) diz que as instituições de ensino superior (IES) encontram-se numa fase de profunda reflexão sobre o seu papel na sociedade e nas respostas necessárias face à evolução do contexto econômico e político. As pressões atuais sobre as instituições de ensino dessa natureza podem-se resumir em três grandes componentes: financeiras, organizacionais e concorrenciais. A inserção de fatores de avaliação, o controle social, a concorrência, entre tantos outros fatores externos impõe às IES um ambiente turbulento que demanda adequação a fim de garantir a sua perpetuação, obrigando-as a repensado o modelo das unidades de ensino, e em consequência repensar suas estruturas organizativas, dos seus processos de atuação e os seus modelos de gestão.

No segmento educacional a gestão estratégica tem sido utilizada como elemento de direcionamento para o alcance de sinergias. Parte-se dos elementos identitários, representados pela missão, visão e valores da organização educativa, de forma a maximizar oportunidades e pontos fortes, proteger-se das ameaças, minimizando os impactos dos pontos fracos sobre o ambiente da instituição. A gestão estratégica institucional deve articular o processo de planejar com a formulação de propósito através de um plano compartilhado para a organização, a escolha da estratégia, a fixação de metas e desafios e a atribuição de responsabilidades para o detalhamento dos planos e projetos necessários a implementação de estratégias no campo da educação.

\section{plupais}


A literatura que trata da implantação da gestão estratégica na educação ainda está em desenvolvimento com um adjetivo de novidade, no entanto, os casos de implantação da metodologia em algumas IES no Brasil, revelam que estas instituições provaram mudanças de melhoria da gestão e ainda contribuíram com subsídios inovadores para a gestão mediante a adoção de uma metodologia de elaboração participativa, o que oportunizou a realização de um trabalho mais competente de direcionamento da escola e da efetivação de seus objetivos. Estudos revelam o uso das ferramentas de gestão estratégica pelas universidades, sejam elas públicas ou privadas (ZAINKO, 1999). As vantagens encontradas nessas IES, que adotaram a gestão estratégica, apontam para um clareamento das perspectivas institucionais de futuro, o enfrentamento dos desafios e o aproveitamento das oportunidades engajando as pessoas no alcance dos objetivos.

A gestão estratégica, nesse campo, caminha por um viés característico da complexidade inerente ao dia-a-dia de "práxis" dos educadores, alunos, colaboradores, público que atende, diversidade de formação de seus recursos humanos, tecnologias, infraestrutura e muito mais. Associam-se também os processos de aprendizagem que se configuram dentro de uma dimensão de poder que são concomitantemente enfatizados. As instituições também se organizam de acordo com seus níveis de poder (formal, cultural e expertise). Esse fato amplia ainda mais a assertividade da adoção de ferramentas de gestão estratégica em ambientes diversificados das relações humanas como no caso da educação (CECÍLIO, 2001).

Para Boaventura e Pimenta (2018), há uma interdependência das áreas finalística (acadêmica) e meio (manutenção), requerendo uma estrutura organizacional e um processo decisório compatível com tais características e que lidem de forma direta com os seguintes tópicos inerentes ao processo de gestão, a saber: formação, conhecimento, tecnologia, qualidade, cultura, descentralização, priorização, comunidade, inclusão, eficiência, eficácia, efetividade, competitividade, diversidade, inclusão, repetência, cidadania, questões acadêmicas e pedagógicas, evasão e equipe. O grande foco da gestão é demonstrar que a ausência de informações confiáveis limita a tomada de decisões internas e externas e que, a médio e longo prazo, isso compromete a permanência da IES. Mintzberg (2009), destaca que a universidade é um tipo particular de organização que sofre influências e pressões externas, o que gera a necessidade e obrigação de reestruturação de suas metas, objetivos e foco, e isso exige uma gestão estratégica.

\section{plurais


Levando-se em consideração a importância da gestão estratégica para o contexto de instituições de ensino superior e considerando a relevância de estudar modelos de gestão estratégica implantados em IES confessionais, apresenta-se nas seções subsequentes, de forma descritiva, o percurso e resultado da implementação de um modelo de gestão estratégica em uma IES dessa natureza - busca-se aqui avaliar oportunidades e limitações.

\section{Metodologia}

Para a realização de uma pesquisa faz-se necessário o planejamento metodológico. Nesse artigo a pesquisa pode ser classificada descritiva de abordagem qualitativa. A natureza qualitativa vale-se das técnicas de coleta de dados de maneira a possibilitar tanto a exploração específica e a elaboração de um modelo visual de explicação para responder à pergunta de partida e atender ao objetivo geral (CRESWELL, 2010).

Optou-se pela pesquisa descritiva, pois nessa tipologia o investigador vai, segundo Minayo (2011), propondo um novo discurso interpretativo, o que foi realizado no trabalho. Desta forma, esta pesquisa se caracteriza como um estudo descritivo, já que tem a intenção de descrever uma realidade institucional, além de registrar, analisar e correlacionar fatos ou fenômenos sem manipulá-los (CERVO, BERVIAN, e SILVA, 2007). De forma prática há que se estabelecer um ciclo para a pesquisa qualitativa, que se divide em três etapas, fase exploratória, trabalho de campo e análise e tratamento de dados.

Para a realização desse estudo, para coleta de dados secundários [Fase 1], partiu-se inicialmente da pesquisa bibliográfica, embasando a pesquisa nos principais conceitos sobre o assunto, pois de acordo com Gil (2009) esse tipo de pesquisa tem sua base em materiais já publicados. Ainda como fonte de dados secundários, foi realizada uma pesquisa documental, que segundo Martins (2008), apesar de haver semelhanças com a pesquisa bibliográfica, não se utiliza materiais de domínio público. No contexto da FADBA, foram consultados, o organograma da instituição, o planejamento estratégico e o Plano de Desenvolvimento Institucional [Fase 1 e 2]. A análise documental permite passar de um documento primário [na origem] para um documento secundário [no artigo], sendo esse a representação estruturada do primeiro (BARDIN, 2010). 
Na Fase 2, para levantamento de dados primários, foram realizadas entrevistas com gestores e aplicação de questionário com os gestores e colaboradores da instituição. O questionário foi aplicado através da ferramenta on-line SurveyMonkey [01 a 17 de junho/2019], com envio direto pelo próprio site e através de e-mail. $\mathrm{O}$ universo da pesquisa foi composto por 57 respondentes, no entanto, em decorrência de inúmeros fatores tais como: período de avaliações na IES, mudança de gestores e consequentemente chefias de departamentos, somente foram obtidas o total de 22 respostas.

Também se utilizou nessa pesquisa uma entrevista com os principais gestores da FADBA que participaram de maneira direta ou indireta do processo de elaboração do planejamento estratégico da instituição - Diretor Geral, diretor de Curso e Intercâmbios interinstitucionais, diretor de Áreas de Formação e professor. A entrevista realizada pode ser classificada como focalizada, que segundo Minayo (2011) destina-se a esclarecer apenas um determinado problema.

A partir dos dados coletados, avaliaram-se os fatores críticos. Para análise dos dados e posicionamentos coletados, foi utilizada a análise de conteúdo. A análise de conteúdo, segundo Bardin (2010) é um conjunto de técnicas de análise das comunicações, não se tratando de um instrumento e sim de um leque de "apretechos". A análise de conteúdo, compreende três etapas básicas: (a) pré-análise; (b) exploração do material; (c) tratamento dos dados e interpretação.

As entrevistas foram gravadas, transcritas e analisadas. Na análise buscou-se realizar o confronto com o objetivo, utilizando-se a forma mais simples - grelha de análise categorial (BARDIN, 2010). Essa técnica privilegia a repetição por frequência dos temas ao olhar o conjunto. Nessa escolha há o risco de perder parte da riqueza de informação, mas por ser um quantitativo pequeno, com um tema e questões muito direcionadas, entende-se que a aplicação da técnica não gerou prejuízos para o resultado final desejado. Buscou-se entender a análise dos conteúdos coletados, à luz do contexto em que a FADBA se encontra. $O$ tratamento do material conduziu a um resultado lógico circunscrito ao objeto de estudo, não sendo possível a generalização, dada as especificidades da FADBA. A análise qualitativa, aqui produzida, não se configura como uma mera classificação de opinião dos informantes. Trata-se da descoberta de códigos sociais a partir das falas e das respostas apontadas nos questionários. A combinação dos resultados e da fundamentação teórica permitiu uma construção contextualizada.

\section{plurais}




\section{Gestão Estratégica na FADBA: Limites e Possibilidades}

A Faculdade Adventista da Bahia (FADBA), que pertence à Rede Mundial Adventista de Educação, uma das maiores redes educacionais do mundo, foi criada como instituição de ensino superior no ano de 2011, mas anteriormente nas mesmas instalações já funcionava o Instituto Adventista de Educação do Nordeste (IAENE), que foi fundado no ano de 1979 com apenas a educação supletiva para 25 estudantes, que também trabalhavam nas instalações da instituição, nos anos seguintes foram implantados a escola de ensino fundamental, o ensino médio e, em 1988, o Seminário de Teologia (SALT). No ano de 1998, efetivamente o IAENE ingressa no ensino superior com a abertura dos cursos de Administração, Pedagogia e Fisioterapia, respectivamente e através de faculdades isoladas, todas mantidas e organizadas dentro do campus. Hoje a instituição conta com nove cursos de graduação (FADBA, 2018).

Todas as áreas de gestão seguem as orientações da mantenedora no que tange a gestão, sendo direcionadas pelos princípios e doutrinas defendidos pela IASD. Dentre os documentos organizacionais de gestão os principais que orientam a administração estão: o planejamento estratégico - PE (2013-2018); o Plano de Desenvolvimento Institucional - PDI (2013-2017); o Projeto Pedagógico Institucional - PPI (2013-2017); o Regimento Interno (RI) e o livro da praxe administrativa eclesiástica - um manual organizacional que é definido pela IASD e que traz as linhas gerais de organização, divisão do trabalho, benefícios e orientação para os funcionários - (FADBA, 2018).

A Faculdade Adventista da Bahia (FADBA), iniciou os estudos do processo de implementação da gestão estratégica em fevereiro de 2013, no ano seguinte culminaram as primeiras ações decorrentes do estudo. A realização dessa etapa de estudo para a elaboração de um Planejamento Estratégico marca uma fase de busca do posicionamento da FADBA em várias frentes de inserção acadêmica. Para uma visão ampliada de como esse processo foi implementado na FADBA, destaca-se que inicialmente a equipe foi escolhida pela liderança local. Após a constituição da equipe formada por pessoas de diferentes áreas, foram realizadas várias reuniões para a criação de um sistema BSC, metodologia escolhida pela gestão, por entender que a FADBA merecia uma metodologia mais atual de gestão estratégica, concretizando-se a etapa de elaboração em 6 fases: 1) Formação da equipe; 2) Avaliação e adequação dos elementos identitários - missão visão e valores [já existentes]; 3) Construção da Matriz SWOT para identificar Pontos Fortes e Fracos, bem como 
ameaças e oportunidades; 4) Elaboração do Mapa estratégico para guiar as diferentes equipes; 5) Definição de objetivos, metas e indicadores e 6) Comunicação do direcionamento estratégico.

Esse percurso evidencia o dito por Parente Filho (2003) sobre a definição da estratégia que demanda coordenação e direção tratando-se ainda de uma ação conjunta, associada à decisão política, que fixam objetivos e asseguram os meios para a execução de operações reais, ou seja, táticas. No caso da FADBA, considerando que a estratégia coorporativa é da IASD, o que essa equipe definiu foi a estratégia de negócios refletindo a questão "Como competiremos em cada negócio?" e a estratégia funcional refletindo a questão "Como alinharemos as áreas funcionais com as estratégias corporativas e de negócios?". A análise SWOT foi um estágio muito importante que direcionou a escolha de uma estratégia de gestão com base no BSC. Foi o momento necessário para o reconhecimento da existência de outros elementos importantes para a efetivação de uma gestão estratégica na instituição.

Através da análise do ambiente interno e externo de FADBA, ficou explicito as suas oportunidades e ameaças e os seus pontos fortes e fracos para o cumprimento de sua missão. As evidências como apontam diferentes autores pode trazer consciência estratégica e estabelecer o propósito de direção que a organização deverá seguir para aproveitar as oportunidades e evitar os riscos (PORTER, 1989; MINTZBERG, 2000).

A análise Swot e a revisão dos valores identitários permitiu a elaboração de um quadro resumo das perspectivas institucionais e suas respectivas estratégias de acordo com o $\mathrm{BSC}$, direcionado ao atingimento da visão de tornar-se um Centro Universitário com excelência nos processos de acreditação, desenvolvendo-se de modo sustentável em harmonia com os valores cristãos que por sua vez permitiu a estruturação de um Mapa Estratégico síntese da estratégia da instituição, configurando-se um elemento visual norteador. Esse processo converteu-se na definição ajustada da missão e visão alinhando a eixos estratégicos diferentes dos que comumente são apresentados nos BSC - Financeiro, Clientes. Processos e aprendizagem e crescimento. A equipe inovou definindo os seguites eixos estratégicos: desenvolvimento espiritual, ensino e aprendizagem, pesquisa e extensão e desenvolvimento organizacional, conforme apresentado no quadro a seguir.

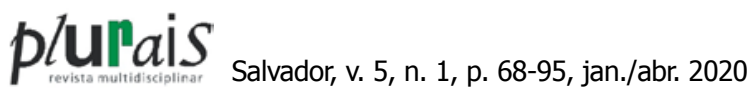


Quadro 1 - Objetivos Estratégicos

\begin{tabular}{|c|c|c|c|}
\hline MISSÃO & VISÃO & EIXOS ESTRATÉGICOS & $\begin{array}{l}\text { OBJETIVOS ESTRA- } \\
\text { TÉGICOS }\end{array}$ \\
\hline \multirow{4}{*}{$\begin{array}{l}\text { O IAENE é uma instituição } \\
\text { educacional da Igreja Ad- } \\
\text { ventista do Sétimo Dia que } \\
\text { forma profissionais capazes } \\
\text { de exercer uma cidadania } \\
\text { responsável, baseada em } \\
\text { valores cristãos, privilegi- } \\
\text { ando seu desenvolvimento } \\
\text { físico, intelectual, social e } \\
\text { espiritual. }\end{array}$} & \multirow{4}{*}{$\begin{array}{l}\text { Tornar-se um Centro } \\
\text { Universitário com exce- } \\
\text { lência nos processos de } \\
\text { acreditação, desenvol- } \\
\text { vendo-se de modo sus- } \\
\text { tentável em harmonia } \\
\text { com os valores cristãos. }\end{array}$} & Desenvolvimento Espiritual & $\begin{array}{l}\text { Promover o desenvolvi- } \\
\text { mento integral da comuni- } \\
\text { dade acadêmica a partir da } \\
\text { implementação do PMDE. }\end{array}$ \\
\hline & & Ensino e aprendizagem & $\begin{array}{l}\text { Desenvolver práticas cur- } \\
\text { riculares interdisciplinares } \\
\text { e transversais, inovadoras, } \\
\text { centradas no princípio da } \\
\text { integralidade cristã. }\end{array}$ \\
\hline & & Pesquisa e extensão & $\begin{array}{l}\text { Desenvolver práticas e } \\
\text { iniciativas de pesquisa e } \\
\text { extensão alinhadas aos } \\
\text { processos de ensino e } \\
\text { aprendizagem. }\end{array}$ \\
\hline & & $\begin{array}{l}\text { Desenvolvimento organiza- } \\
\text { cional }\end{array}$ & $\begin{array}{l}\text { Tornar-se um Centro Uni- } \\
\text { versitário de referência } \\
\text { regional, com qualidade } \\
\text { reconhecida nos processos } \\
\text { administrativos, pedagógi- } \\
\text { cos e financeiros. }\end{array}$ \\
\hline
\end{tabular}

Fonte - Relatóris Interno FADBA (2014).

A seguir, para cada objetivo estratégico, foram em consonância com as diferentes equipes, definidas metas que se organizavam da seguinte forma: 1) Objetivo Estratégico; 2) Objetivo (s) Específico (s); 3) Meta; 4) Indicador de Controle - nesse caso verificando o estágio em 2013 e projetanto 2014 a 2018.

Após a consolidação dessa etapa a gestão da FADBA passou para a fase de comunicação com os diferentes stakeholders. O BSC da FADBA, conforme prevê a bibliografia consultada tornou-se um sistema de gestão que traduz a estratégia da IES em objetivos, medidas, metas e iniciativas de fácil entendimento pelos participantes. Tornou-se também uma ferramenta gerencial útil para capturar, descrever e transformar os ativos intangíveis de FADBA em valor para os stakeholders. Foi constituído como um sistema balanceado de gestão para promover um equilíbrio entre as principais variáveis estratégicas, a saber: equilíbrio entre os objetivos de curto e longo prazos; equilíbrio

\section{plurais}


entre o foco interno e o ambiente externo da organização; equilíbrio entre medidas financeiras e medidas do capital intelectual; e equilíbrio entre os indicadores de ocorrência e os indicadores de tendências (KAPLAN e NORTON, 2017).

A IES optou por construir um modelo que não deixasse a estratégia corporativa com um conjunto aleatório de diferentes componentes, estruturou um sistema de partes interdependentes, cuidadosamente ajustadas. Kaplan e Norton (2017, p.45) dizem que a gestão estratégica serve para demonstrar as propostas de valor e esse valor - instituição confessional - é privilegiado no mapa quando desenvolve um eixo denominado "Desenvolvimento Espiritual".

Essa escolha da equipe gestora buscava sinergias coorporativas a fim de obtenção de benefícios para o desempenho da IES. Aqui é possível observar o que Herrero Filho (2005) destaca: compartilhamento da visão entre a equipe executiva e os colaboradores; direcionamento dos esforços para os objetivos considerados prioritários; percepção acurada das oportunidades do ambiente externo; identificação e monitoramento ágeis das mudanças do ambiente externo; e sistemática análise crítica da estratégia e da sua consistência, em face das mudanças no ambiente.

O processo da FADBA até essa etapa reflete a formulação da estratégia, que apresenta a estratégia pretendida. Mintzberg (2000) adverte para a possibilidade de distanciamento entre o planejado e o executado, pois para o autor a estratégia é um processo contínuo e nem sempre a estratégia realizada coincide com a estratégia pretendida, pois as mudanças, as incertezas, as novidades e a criação de novos conhecimentos podem afetar o processo. $\mathrm{O}$ autor ainda destaca que a criação e a implementação da estratégia são sensíveis, sendo a implementação um processo problemático para a maior parte das empresas no mundo. Assim, por entender que a formulação da estratégia se deu de forma satisfatória para o primeiro ciclo, coube, nessa pesquisa, avaliar se a implementação também foi bem-sucedida. Após a apresentação da fase de consecução, cabe analisar a percepção dos participantes em relação aos resultados do primeiro ciclo de gestão estratégica. Traz-se aqui o resultado dos dados coletados via questionário e entrevista.

Antes de discutir efetivamente a implementação cabe caracteriza os respondentes. Quanto as entrevistas, foram consultados: Diretor Geral, diretor de Curso e Intercâmbios interinstitucionais, diretor de Áreas de Formação e professor. Quanto aos questionários, os respondentes são gestores e colaboradores, em uma amostra de vinte e dois (22) respondentes. Os resultados apontam: sete

\section{plurais}


(7) do sexo feminino e quinze (15) do sexo masculino; nove (9) possuíam idade predominante na faixa etária de 28 a 37 anos e sete (7) na faixa etária entre 48 a 57 anos. A maioria (9), são chefes de departamento, apenas um (1) é líder de equipe. Dentre os quatro (4) respondentes que indicaram a alternativa "outra", três (3) são professores e 1 é assistente social. Assim, dezoito (18) são gestores. Onze (11) deles possuem 10 anos ou mais de atuação na FADBA.

O período da análise dessa pesquisa compreende os anos 2014-2019, o que significa que $50 \%$ dos entrevistados estavam na instituição durante os anos de implementação da gestão estratégica. Os cargos de chefe de departamento, coordenador, gerente e diretor, formam a equipe de gestores da instituição, conferindo aos achados dessa pesquisa uma forte ferramenta de análise das reais condições do processo de implementação da gestão estratégica na FADBA, pois o papel do gestor é evitar a esterilidade tão frequentemente encontrada naqueles que se isolam das operações (MINTZBERG, 2009).

No processo de entrevistas com os gestores diretos, as falas revelam envolvimento e motivação para a elaboração do planejamento estratégico, conforme os relatos apresentados a seguir:

[...] quando nós iniciamos o processo de planejamento estratégico foi chamado uma comissão de planejamento estratégico, na época liderada pelo X, que foi uma pessoa escolhida pela formação e pela experiência para que fizesse a liderança dessa equipe [...] foram convidados a participar dessa comissão de planejamento os principais gerentes [.... O modelo utilizado foi o modelo BSC [...] [Entrevista do gestor 2].

[...] Na realidade foi uma união de desejo porque o grupo da área de administração também já avaliava a necessidade da instituição de ter um planejamento estratégico que tivesse pelo menos um tempo de quatro anos ou cinco anos coincidindo com o plano de desenvolvimento institucional proposto pelo MEC, então o plano era que o planejamento estratégico dialogasse com o PDI [...] [Entrevistado gestor 4].

O Planejamento Estratégico da FADBA, segundo dezoito (18) respondentes, é conhecido, tendo sido lido por onze (11) e nunca lido por cinco (5) e utilizado como guia de atividades por apenas dois (2) dos respondentes, aspecto que sinaliza um problema na fase implementação e na efetividade do PE. Agrega-se a este cenário a declaração de dois (2) respondentes que afirmaram não conhecer o documento e apenas saber da sua existência. 
Dentre as questões atinentes a implantação da gestão estratégica está a aceitação, o BSC não existe só para criar coerência e uniformidade organizacional, mas sim, para antecipar demandas e necessidades, proporcionar respostas rápidas às crises e enfrentar melhor os riscos e incertezas. Como diz Barbosa (2008), a comunicação pode ser considerada como um aspecto crítico por se tratar de um processo através do qual ocorre a troca de informações relevantes sobre a empresa entre os colaboradores e gestores, sobre as mudanças que nela ocorrem. É preciso comunicar e dar reforço a essa comunicação.

Quando questionados a respeito da participação na elaboração do BSC da FADBA, apenas cinco (5) dos respondentes afirmaram ter participado efetivamente deste processo e seis (6) afirmam que não foram convidados. A permanência dos principais atores que elaboraram o plano por um tempo na instituição garante sua implementação. Para Xavier e Sobrinho (2002) um plano é um processo participativo que visa a melhoria da gestão da instituição e demanda a participação efetiva da comunidade interna. O não envolvimento pode impactar de forma significativa na efetividade das ações necessárias - metas e indicadores podem ser relegados a segundo plano.

O alinhamento entre as atividades laborais e Planejamento Estratégico da FADBA é de fundamental importância para este trabalho porque revela objetivamente qual de fato tem sido os impactos da primeira etapa de implantação aqui estudada. Mintzberg (2009) ressalta que a estratégia é um modelo que coaduna de forma interdependente objetivos, políticas e ações com vistas a identificar uma vantagem competitiva. Sete (7) dos respondentes afirmam que o trabalho que desenvolve possui alinhamento com a estratégia institucional, porém doze (12) afirmam que embora mantenham este alinhamento não tem clareza sobre qual de fato é a estratégica institucional.

A Faculdade Adventista da Bahia (FADBA) é uma instituição educacional confessional mantida pela Igreja Adventista do Sétimo Dia (IASD) que desenvolve em todas as suas organizações a consolidação de seus princípios e valores como maneira de valorização do ser humano e da sua importância representativa no contexto mundial. O conhecimento e envolvimento na missão da igreja é a base filosófica que confere a FADBA o nome Adventista. Na mesma proporção da clareza dos objetivos denominacionais, a gestão estratégica na FADBA se propõe alinhar também os objetivos e as atividades laborais.

\section{plurais}


Foi questionado aos respondentes se na execução das atividades laborais por eles desenvolvidas existe a preocupação de atender os objetivos estratégicos da FADBA. Dezessete (17) dos respondentes afirmaram que possuem esta preocupação, mas destes, dez (10) declaram que não tem clareza quais são estes objetivos. Mais uma vez observa-se o distanciamento entre o planejado e o executado, cabendo destaque para o não reconhecimento por parte da equipe.

Esse fato remete a necessidade de uma autoavaliação institucional que busque a explicitação e socialização dos objetivos estratégicos. No entanto, o que mais importa em todo o processo é a capacidade da empresa de se auto avaliar e em seguida adotar estratégias que potencializem o seu negócio (MINTZBERG, 2009).

Para o atingimento das metas estabelecidas em um planejamento é fundamental que os colaboradores no desenvolvimento de suas atividades busquem atendê-los. Através desta pesquisa foi constado que entre os vinte (20) respondentes dezenove (19) afirmam que se preocupam em atender estas metas, porém dez (10) não tem clareza sobre quais são elas. Mintzberg (2009), explicita que os gerentes (colaboradores) fazem parte de um grupo pelo meio do qual as "coisas" acontecem, assim, estar atento as demandas desse grupo favorecem a implantação da estratégia.

Ao serem questionados sobre os valores da FADBA, dezoito (18) respondentes afirmaram conhecer e compartilhar dos mesmos valores e apenas dois (2) afirmaram conhecer, mas não ter clareza sobre eles. Visto que a instituição estudada é de perfil confessional, é esperado que os valores dos seus colaboradores tenham alinhamento com ela. Tal hipótese constata-se quando dezoito (18) dos respondentes afirmam que além de conhecer os valores da FADBA compartilham dos mesmos. Esse aspecto é destacado nos eixos estabelecido. Há um pilar com a denominação de "Desenvolvimento Espiritual”, que propõe o fortalecimento da fé e comprometimento pessoal e coletivo com a missão, através de um plano de reavivamento envolvendo toda comunidade acadêmica. $\mathrm{O}$ fato desses colaboradores serem conhecedores e participes dos mesmos valores denominacionais da FADBA, confere para eles a possibilidade, como diz Mintzberg (2009), de resolverem as crises "colocando a mão na massa".

A missão da FADBA para maioria dos respondentes (17) é conhecida e guia para realização do trabalho desenvolvido por estes colaboradores. É importante o fato de que dentre os respondentes nenhum afirma desconhecer a missão da instituição confessional estudada. A visão por sua 
vez, também é conhecida pela totalidade dos respondentes, sendo que quatro (4) afirmam não ter clareza dessa missão.

Quando se perguntou aos respondentes se eles acreditavam que as decisões estratégicas tomadas na FADBA tinham como base o Planejamento Estratégico vigente, a maioria, quatorze (14), afirmaram que sim, porém, sendo difícil a percepção deste alinhamento, e cinco (5) dos respondentes afirmam que não acreditam e que não conseguem perceber esse alinhamento. Para minorar os impactos as organizações/instituições precisam realizar três atividades integradas entre si: a gestão do ambiente; a gestão da organização/instituição e a gestão do alinhamento entre a estratégia e a empresa. A gestão estratégica serve para demonstrar as propostas de valor, ou seja, demonstrar como a administração corporativa extrai mais valor dos negócios que possui e opera, pois recursos, negócio e organizações estão alinhados uns com os outros. Para Mintzberg (2009) é fundamental que o estrategista tenha conhecimento amplo das metas, desafios e estratégias da organização.

A clareza das metas de avaliação utilizadas pela FADBA, em relação aos seus colaboradores e aos Departamentos onde estes atuam, é considerada por sete (7) dos respondentes como não existentes. Três (3) respondentes afirmam que possuem clareza das metas que devem atingir e dez (10) dizem conhecer, mas afirmam não ter clareza.

Foi pedido aos respondentes que indicassem a sua participação em reuniões sobre gestão estratégica, avaliação estratégica e planejamento estratégico e quinze (15) dos respondentes afirmaram ter participado. O distanciamento entre o planejado e o executado volta a aparecer nessa questão. $\mathrm{O}$ que se consolida como uma vulnerabilidade do processo.

Em relação a crença da tomada de decisão do líder imediato ter como base o plano estratégico da FADBA, oito (8) dos respondentes afirmaram que não conseguiam avaliar este processo e dez (10) afirmaram que somente às vezes acreditam que o plano estratégico é basilar para o líder imediato.

Mota (1992) destaca dentre as implicações que dificultam o sucesso da estratégia está a débil articulação entre o planejado e o executado no dia-a-dia. A fala de um dos gestores diretos entrevistados sobre esse aspecto revela a necessidade de alinhamento entre o planejado e o executado. Quando questionado a resposta foi a seguinte:

\section{plupais


[...] Parcialmente, eu acho que nos primeiros dois anos isso aconteceu mas aconteceu um problema essencial para que isso não tivesse continuidade houve um conflito direto porque quem sabe na primeira avaliação do MEC ou nas primeiras avaliações a gente percebeu que o documento que o MEC utilizava para avaliar a instituição não era o planejamento estratégico, o planejamento utilizado pelo MEC era o PDI, e o PDI não estava alinhado com o planejamento estratégico. Isso quer dizer, muito dos objetivos, muitas das metas traçadas, muito do que estava sendo feito não estava no PDI e de certa forma o que estava no PDI não estava muito claro como seria e qual era a materialização disso, qual era a comprovação disso. Então começou a se perceber ai em 2016 para frente que não adiantava ainda seguir a risca o planejamento estratégico e esquecer o PDI e ai o planejamento estratégico perdeu um pouco de força nesse processo [...][Entrevistado gestor 3].

Diante da questão que investiga a percepção dos respondentes sobre a existência de mudanças para uma gestão mais estratégica e profissional a partir da elaboração e apresentação do plano estratégico vigente, doze (12) dos respondentes afirmaram que na maioria das vezes percebem as mudanças. Nesse aspecto, os gestores diretos têm compreensões distintas, há os que acreditam que as mudanças são parte de um processo mais paulatino e não mágico e aqueles que ainda não percebem as mudanças ocorrendo com a intensidade necessária para uma efetiva transformação do paradigma de gestão, como podemos ver a seguir nas falas:

[...] Eu vejo que efetivamente o planejamento estratégico ele contribuiu para uma otimização das tomadas de decisões e dos direcionamentos institucionais no entanto percebo que em virtude de mudança administrativa mais pro final do quinquênio que havia sido proposto ele sofreu alterações por mudanças no gerenciamento institucional o que acabou enfraquecendo e até mesmo tirando o direcionamento que o próprio planejamento havia sido proposto para o final de 2018, que pegava a última parte desse quinquênio [...] [Entrevistado gestor 2].

[...] Não vejo muita diferença não, acho que houve uma tentativa muito interessante, o plano estratégico precisa de fato ser uma coisa olhada com seriedade, estamos de novo começando um novo processo de planejamento estratégico. Eu espero que esse surta mais efeito do que o outro, seja realmente uma coisa que atenda aos anseios da comunidade acadêmica e não necessariamente a visão específica de uma diretoria, ter sempre esse cuidado quando se pensa em planejamento estratégico para que ele seja de fato colaborativo que as pessoas se sintam participes, para que elas desejem 
acompanhar, que não seja um instrumento apenas de lógica instrumental [...] [Entrevistado gestor 4]

Os ativos do conhecimento e a capacidade de aprender de uma organização são fontes importantes de vantagem competitiva. Há nesse processo, ao observar a fala dos gestores, o desejo de alteração no sentido e uso do planejamento.

Foi solicitado aos respondentes que indicasse qual fator era mais relevante para a gestão estratégica. Oito (8) dos respondentes afirmaram que é a "natureza da organização". O respondente que indicou a opção "outra" especificou que não consegue identificar um aspecto que favoreça a gestão estratégica da FADBA. Aqui fica evidenciada a influência da identidade organizacional, pois os valores são traduzidos no BSC e estão arraigados nos participantes.

Em seguida, foi perguntado aos respondentes qual aspecto mais relevante para causar desfavorecimento da gestão estratégica da FADBA. A "cultura da organização" e a "ação das lideranças" foram indicadas como as mais relevantes. Foram indicados ainda, pelos respondentes, que "não é somente uma coisa e sim várias, sendo elas: Transparência da gestão, cultura organizacional, engajamento das equipes, ação das lideranças" e que "a condição financeira do país tem tornado difícil seguir o plano estratégico como foi elaborado, porque muitas coisas mudaram no cenário global”.

Quando ao nível de participação nas decisões da FADBA trezes (13) dos (vinte) 20 respondentes se declararam participantes, sendo quatro (4) participantes ativos; nove (9) que embora participem acreditam que poderiam fazer mais. Para Mintzberg (2009), o que mais importa em todo o processo é a capacidade da empresa de se autoavaliar e em seguida adotar estratégias que potencializem o seu negócio. Assim, elevar o nível de participação dos gestores nas decisões é imprescindível e estrategicamente necessário.

Por fim, foi perguntado aos respondentes se eles acreditavam que o planejamento estratégico gerou melhoras nas relações da FADBA onde quinze (15) respondentes afirmam que sim e destes, oito (8) afirmam também que ainda se tem muitos problemas de transparência na gestão. Assim, é possível identificar que o processo de implementação da gestão estratégica da FADBA, não é uma etapa consolidada, carecendo ainda de amadurecimento e reestruturação, com relação direta aos principais gestores e colaboradores que estão a frente da instituição.

\section{plurais}


Ao adotar a gestão estratégica, na percepção dos participantes, observa-se que na FADBA já é possível verificar um aprendizado no processo, pois a equipe gestora e os colaboradores compartilham da identidade institucional. Nesse caso, merece destaque o fato dos valores estarem ancorados na religião que comungam; o que fortalece e favorece esse elemento; há objetivos prioritários definidos nos diferentes eixos, mas ainda não introjetados nos colaboradores.

É importante que a FADBA esteja atenta à necessidade de adequação e melhoria do seu modelo de gestão estratégica, pois o sucesso de uma IES depende da qualidade dos serviços que presta a comunidade e essa qualidade, por sua vez, depende do Projeto de Desenvolvimento Institucional, projeto pedagógico e desempenho dos professores, colaboradores e gestores dos mais diferentes níveis institucionais, requerendo uma gestão estratégica de todos os recursos.

\section{Considerações Finais}

Toda IES possui características e cultura próprias o que pode influenciar no processo de gestão estratégica. No modelo da FADBA observa-se dois fatores relevantes valores arraigados e uso do BSC.

Ao buscar descrever o modelo de gestão estratégica adotado na IES estudada, após acesso ao documento denominado "Planejamento Estratégico FADBA - 2014-2018", ficou explicito a adoção do modelo de Gestão Estratégica com uso de BSC. O BSC, é uma ferramenta gerencial com sistema de mensuração que se concentra na estratégia da organização, buscando criar valor sustentável no futuro. Como modelo para uma IES confessional, pode-se afirmar que há adequação, pois explicita os valores institucionais alinhando-os para as atividades finalísticas.

Ao caracterizar o perfil do público-alvo e a sua influência no processo de gestão estratégica, verificou-se tratar de um conjunto de atores que na sua maioria é do sexo masculino, com idade predominante na faixa etária de 28 a 57 anos. São chefes de departamento, líderes de equipe, professores e assistente social. Dos 22 respondentes, 18 eram gestores. No conjunto de respondentes $50 \%$ possui 10 anos ou mais de atuação na FADBA. Aqui cabe apresentar a primeira limitação do estudo - concentração da aplicação do instrumento de coleta de dados com a equipe gestora. A consulta mais ampla permitiria avaliar a inclusão, ou não, da equipe de colaboradores e não somente de lideranças no processo de formulação; a qualidade da disseminação da comunicação 
em todos os níveis organizacionais; e, por fim, o engajamento na execução da estratégia, difícil etapa de implementação de uma nova sistemática de gestão.

Quando se buscou identificar os principais impactos gerados com a adoção da gestão estratégica na IES a fala dos gestores foi mais adequada a essa finalidade para eles o planejamento contribuiu para uma otimização das tomadas de decisões e mudou o direcionamento institucional. A mudança da sistemática explicitou a estratégia da IES, viabilizando o que os autores chamam de formulação. Entretanto, há ainda lacunas na implementação. A equipe, de diferentes formas, afirma conhecer, mas não demonstra engajamento, o que pode ser resultado de algumas falhas apresentadas na literatura: implementação lenta; problemas internos; intensificação das crises externas; gestão ineficaz; falta de preparo dos colaboradores; falta de colaboração entre os pares; comunicação e treinamento insuficientes; falhas de liderança e monitoramento inadequado.

Assim, ao buscar identificar a percepção de gestores e colaboradores em relação ao resultado da implementação da gestão estratégica na Faculdade Adventista da Bahia (FADBA) no período de 2014 a 2018, pode-se afirmar que a formulação adequada do mapa estratégico já tem contribuído de maneira significativa para o desenvolvimento institucional, mas destaca-se que a FADBA necessita analisar as fortalezas e debilidades decorrentes desse período de implementação para alcançar os objetivos delineados no Planejamento Estratégico para a gestão.

Com isso, é possível dizer que essa pesquisa pode oferecer, para a instituição, informações importantes para embasarem as medidas necessárias que favoreçam o processo de consolidação e apontar novos caminhos de pesquisa para a avaliação da efetividade do ciclo. A pesquisa mais uma vez corroborou para a visão de que as fortalezas da instituição são os pilares para a consolidação do processo de gestão estratégica. A depender de quanto o processo de implementação da gestão estratégica tenha sido compartilhado com os demais atores da instituição, maior será a probabilidade de alcance dos objetivos em curto prazo. A análise da implementação da gestão estratégica na FADBA, revelou a necessidade de uma reestruturação operacional que obedeça às diretrizes planejadas.

Quando se analisa a percepção dos gestores que participaram efetivamente na elaboração do plano, observam-se ações delineadas para que o planejamento estratégico alcance o que se está proposto, no entanto, os dados analisados revelam que há uma descontinuidade entre o planejado

\section{plupais


e o de fato executado, expondo assim a fragilidade da FADBA em consolidar sua gestão com base em ferramentas estratégicas. Esse aspecto pode ser ponderado quando se afirma ser esse o primeiro ciclo de gestão.

Há limites claros na elaboração desse trabalho. Um deles é a evidenciação da influência da IASD no processo de implantação de uma gestão estratégica, o que levanta o seguinte questionamento: qual o modelo de "gestão" da mantenedora para suas IES e sua política denominacional? Esse aspecto que, pode caracterizar uma limitação, também se reverte em oportunidades, suscitando ao investigador recortes inovadores.

\section{REFERÊNCIAS}

ALMEIDA FILHO, Naomar Monteiro de et al. Mapa de Rede de Impactos para gestão estratégica na universidade. Educ. Real. Porto Alegre, v. 39, n. 1, p. 277-301, mar. 2014. Disponível em <http://www.scielo.br/scielo.php?script=sci_arttext\&pid=S2175-62362014000100016\&ln$\mathrm{g}=\mathrm{pt} \& \mathrm{nrm}=\mathrm{iso}>$. Acesso em 20 out. 2019.

ANSOFF, H. Igor. A nova estratégia empresarial. São Paulo Atlas, 1990.

BARBOSA, C. A. V. Aspectos críticos da implementação do modelo de gestão por competências em duas empresas de manufatura. 2008. 146 f. Dissertação. Universidade Católica de Santos - UNISANTOS. Disponível em: $<$ http://biblioteca.unisantos.br:8181/bitstream/ tede/445/1/Catarine\%20Aparecida\%20Vieira\% 20Barbosa.pdf $>$. Acesso em: 17 de junho de 2019. 1

BARDIN, Laurence. Análise de conteúdo. Lisboa: Edição 70, 2010.

BOAVENTURA, E. M.; PIMENTA, L. B. Processo de Gestão na Universidade multicampi. Disponível em: < https://revistas.unifacs.br/index.php/redu/article/viewFile/5630/3551>. Acesso em: 18 de agosto de 2019.

BULGACOV, Sergio et al. Administração estratégica: teoria e prática. São Paulo: Atlas, 2007.

CAGGY, Ricardo Costa e BENEVIDES, Tânia Moura. Estrategic Canvas: conduza a estratégia do seu negócio por caminhos dinâmicos e criativos de forma inovadora. Rio de Janeiro: Alta Books, 2018. 
CERVO, Amado L.; BERVIAN, Pedro A.; SILVA, Roberto da. Metodologia científica. $6^{\mathrm{a}}$ ed. São Paulo: Pearson, 2007.

COSTA, Eliezer Arantes da. Gestão Estratégica: da empresa que temos para a empresa que queremos. 2. ed. São Paulo: Saraiva, 2015.

CRESWELL, Jonh W. Projeto de Pesquisa: métodos qualitativo, quantitativo e misto. $3^{\mathrm{a}}$ ed. Porto Alegre: Artmed, 2010.

FADBA (FACULDADE ADVENTISTA DA BAHIA). Plano de Desenvolvimento Institucional (PDI). Cachoeira: Faculdade Adventsita da Bahia (FADBA), 2014.

. Sobre a Faculdade Adventista da Bahia, 2018. Disponível em: <www.adventista.edu. br>. Acesso em: 29 de janeiro de 2018.

FERNANDES, B.R. Gestão estratégica de pessoas com foco em competências. Rio de Janeiro: Elsevier, 2013.

GIL, A. C. Como elaborar projetos de pesquisa. 4 ed. São Paulo: Atlas, 2009.

HERRERO FILHO, Emilio. Balanced Scorecard e a gestão estratégica: uma abordagem prática. Rio de Janeiro: Elsevier, 2005.

KAPLAN, R. S.; NORTON, D. P. A estratégia em ação: Balanced Scorecard. 21. ed. Rio de Janeiro: Elsevier, 1997.

. Alinhamento: Utilizando o balanced scorecard para criar sinergias corporativas. Rio de Janeiro: Alta Books, 2017.

MINTZBERG. H.; AHLSTRAND, B.; LAMPEL, J. Safári de estratégia. Porto Alegre: Bookman, 2000.

MINTZBERG. H.; AHLSTRAND, B.; LAMPBEL, J. O processo da estratégia: conceitos, contextos e casos selecionados. Porto Alegre: Bookman, 2009.

PARENTE FILHO, J. Planejamento Estratégico na Educação. Brasília: Plano. 2003.

PORTER, Michel. Vantagem competitiva: criando e sustentando um desempenho superior. 12. ed. Rio de Janeiro: Campus, 1989.

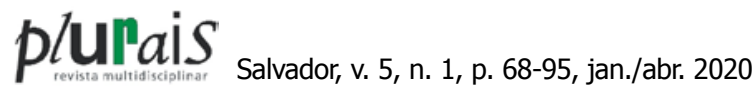


RIBEIRO, Denise de Andrade. Trajetória institucional da universidade brasileira - a UFBA como reflexo e modelo. Disponível em: http://www.adm.ufba.br/sites/default/files/publicacao/ arquivo/tese_denise_de_andrade_ribeiro.pdf $>$. Acesso em: 18 de junho de 2019.

SANTOS, A. V. Adequação de um modelo para a avaliação de IES - Instituições de Ensino Superior - pelos critérios de excelência do PNQ - Prêmio Nacional da Qualidade. Dissertação. Mestrado em Engenharia da Produção. Universidade Federal de Santa Catarina, 2003.

VOLTOLINI, Ricardo. Terceiro setor: planejamento e gestão. 2. ed. São Paulo: SENAC, 2004.

XAVIER, A. C. da R., SOBRINHO, J. A. Como elaborar o Plano de Desenvolvimento da Escola. Brasília: Fundescola/FNDE/MEC, 2002.

ZAINKO, Maria Amélia Sabbag. Planejamento Estratégico em Universidades Públicas. Tese (Doutorado em Educação) USP, 1999.

Recebido em: 01 de abril de 2020.

Inserido em: 20 de maio de 2020.

Esta obra está licenciada com uma Licença Creative Commons Atribuição 4.0 Internacional. 